\title{
Utilização de biopolímero no tratamento de efluentes da indústria de papel e celulose por Processo Oxidativo Avançado
}

\author{
Use of biopolymer in pulp and paper industry \\ wastewater treatment by Advanced Oxidative Process
}

\author{
Kely Viviane de Souza1, Elis de Oliveira Lopes², Daniel Bartiko33, \\ Carlos Magno de Souza Vidal' ${ }^{1}$ e Jeanette Beber de Souza ${ }^{1}$
}

\begin{abstract}
Resumo
A indústria de papel e celulose produz elevado volume de efluente, o qual geralmente apresenta alto valor de cor e concentração de matéria orgânica. A maioria dos componentes presentes no efluente são difíceis de eliminar por processos convencionais de tratamento de águas residuárias. Neste contexto, estudos de alternativas que melhorem significativamente a qualidade do efluente e que representem minimização dos impactos associados à disposição deste no ambiente são necessários. Dentre tais alternativas, destacam-se os Processos Oxidativos Avançados (POA) por serem processos destrutivos e não seletivos de poluentes. Dentre os POA, o processo foto Fenton tem merecido atenção devido à elevada eficiência e simplicidade operacional. O presente estudo objetivou avaliar a eficiência do processo foto Fenton utilizando $\mathrm{Fe}^{2+}$ imobilizado em esferas de quitosana como catalisador, bem como a capacidade de reutilização do material, visando dar polimento ao efluente de uma indústria de papel e celulose. $O$ processo foi realizado em reator fotoquímico de bancada, com $250 \mathrm{~mL}$ de efluente, $\mathrm{pH}=7,2,0 \mathrm{~g}$ de esferas de quitosana com $\mathrm{Fe}^{2+}$ (EQFe), e $400 \mathrm{mg} \cdot \mathrm{L}^{-1}$ de $\mathrm{H}_{2} \mathrm{O}_{2}$. Os parâmetros avaliados após 90 minutos de tratamento foram: turbidez, cor, DQO e fenóis totais. Os resultados demonstraram que durante 90 minutos de tratamento houve redução de $59,0 \%$ da turbidez, $99,6 \%$ da cor, $74,9 \%$ da DQO e $87,2 \%$ de fenóis, utilizando 400 mg. - $^{-1}$ de $\mathrm{H}_{2} \mathrm{O}_{2}$ e $2 \mathrm{~g}$ de massa de (EQFe). Nos ensaios realizados, observou-se que o ferro permaneceu sorvido na matriz, o que possibilitou a reutilização das EQFe em seis ciclos, mantendo a eficiência na degradação. Os resultados indicam a potencialidade do emprego do processo foto Fenton na remediação de efluentes de indústrias de papel e celulose.
\end{abstract}

Palavras-chave: Efluente de papel e celulose; Foto Fenton, Quitosana, Degradação de fenóis.

\begin{abstract}
The pulp and paper industry produces a high volume of effluents, which usually have high color value and organic matter concentration. Most components of the effluent are difficult to dispose of using conventional wastewater treatment processes. Thus it is necessary to explore alternatives that improve the effluent quality and minimize the environmental impact associated with its disposal. Among these alternatives, the Advanced Oxidation Processes (AOP) have been highlighted because they are destructive and nonselective processes of pollutant removal. Among the AOP, the photo-Fenton process has received attention due to its high efficiency and operational simplicity. The present study aimed to evaluate the photo-Fenton process efficiency using $\mathrm{Fe}^{2+}$ beads immobilized on chitosan as a catalyst in the polishing of effluent from a pulp and paper industry, as well as the reusability of the catalyst material. The process was carried out in a bench-top photochemical reactor with $250 \mathrm{~mL}$ of effluent $(\mathrm{pH} 7), 2.0 \mathrm{~g}$ of chitosan beads with $\mathrm{Fe}^{2+}(\mathrm{CBFe})$, and $400 \mathrm{mg} / \mathrm{L}$ of $\mathrm{H}_{2} \mathrm{O}_{2}$. The parameters evaluated after $90 \mathrm{~min}$ of treatment were: turbidity, color, chemical oxygen demand (COD), and total phenols. The results showed that turbidity, color, COD, and total phenols were reduced by $59.0 \%, 99.6 \%, 74.9 \%$, and $87.2 \%$, respectively. The analysis also showed that the iron remained absorbed in the matrix, which allowed the reuse of CBFe over six cycles without losing efficiency of degradation. These results indicate that the photo-Fenton process can be used in the remediation of effluents from pulp and paper industries.
\end{abstract}

Keywords: Pulp and paper effluent, Photo Fenton, Chitosan, Phenols degradation.

1Professor(a) Adjunto(a) do Departamento de Engenharia Ambiental. UNICENTRO - Universidade Estadual do Centro-Oeste. Campus de Irati. - PR 153 - Km 7 - Riozinho - 84500-000 - Irati, PR, Brasi. E-mail: kelyvdesouza@gmail.com; cacavidal@yahoo.com.br; jeanettebeber@yahoo.com.br

${ }^{2}$ Mestranda em meio Ambiente Urbano e Industrial e MBA em Gestão Ambiental. UFPR - Universidade Federal do Paraná / Centro Politécnico. Av. Coronel Francisco H. dos Santos, 100 - Jardim das Américas- 81530-000- Curitiba, PR, Brasil. E-mail: elis lopes@outlook.com

32Doutorando em Engenharia Ambiental. UFSC - Universidade Federal de Santa Catarina. Campus Reitor João David Ferreira Lima, s/n - Trindade - 88040-900 - Florianópolis - SC, Brasil. E-mail: danielbartiko@hotmail.com 
Souza et al. - Utilização de biopolímero no tratamento de efluentes

da indústria de papel e celulose por Processo Oxidativo Avançado

\section{INTRODUÇÃO}

Desde 2012, o Brasil é o quarto produtor mundial de celulose e nono na produção de papel (IBÁ, 2015). A escala de produção das indústrias costuma integrar todas as etapas do processo produtivo, atuando desde a exploração florestal até a comercialização da celulose e/ou do papel. Assim, este setor é altamente dependente de recursos naturais (madeira e água, por exemplo) e também grande gerador de resíduos, os quais têm potenciais impactos sobre a qualidade do ar, água e solo (COVINICH et al., 2014).

Em relação aos recursos hídricos, as indústrias de papel e celulose estão entre as que utilizam maior volume de água, cerca de $60 \mathrm{~m}^{3}$ para cada tonelada de celulose seca ao ar (TSA) produzida. Tal consumo está relacionado ao volume de efluente líquido que é gerado ao longo do processo, o qual deve ser tratado previamente ao seu lançamento nos corpos receptores (KAMALI; KHODAPARAS, 2015).

As características do efluente produzido em indústrias de papel e celulose dependem de inúmeros fatores, como a espécie e origem da madeira utilizada, processo empregado na polpação e branqueamento (se houver), tipo de papel produzido, processos tecnológicos utilizados, entre outros (COVINICH et al., 2014). De modo geral, o mesmo apresenta elevada carga orgânica, forte coloração e turbidez, além da presença de diversas espécies de caráter recalcitrante, como a lignina (KAMALI; KHODAPARAS, 2015; COVINICH et al., 2014). Assim, as indústrias de papel e celulose devem contar com um sistema que seja capaz de tratar o efluente em níveis suficientes para atender às legislações vigentes (Resoluções CONAMA 357/2005 (BRASIL, 2005) e CONAMA 430/2011 (BRASIL, 2011) por exemplo) em relação a sua qualidade e disposição final.

Segundo Bonfim et al. (2013), é comum as indústrias de papel e celulose tratarem os efluentes produzidos em todas as etapas do processo produtivo em uma única estação de tratamento, composta por tratamento primário (decantadores) e secundário (reatores biológicos). No entanto, tais métodos apresentam limitações na remoção de cor e na degradação de poluentes não biodegradáveis (COVINICH et al., 2014; PEREIRA; FREIRE, 2005). Em função disso, torna-se necessário que as indústrias realizem também tratamento a nível terciário de seu efluente, permitindo assim o atendimento às legislações vigentes e a possibilidade da reutilização da água no próprio processo produtivo (COVINICH et al., 2014).

Com essa finalidade, a aplicação dos Processos Oxidativos Avançados (POA) na remediação de compostos poluentes recalcitrantes tem atraído grande interesse, difundindo-se bastante nos últimos anos. Descritos em 1973, os POA são tratamentos químicos baseados na geração do radical hidroxila $(\bullet \mathrm{OH})$, que é um agente altamente oxidante $\left(\mathrm{E}^{\circ}=2,8 \mathrm{~V}\right)$, capaz de promover a mineralização de vários compostos poluentes, por meio de uma série de reações químicas.

Os POA são processos limpos e não seletivos, podendo ser aplicados para mineralizar compostos orgânicos tanto em fase aquosa como em fase gasosa ou adsorvidos em uma matriz sólida (COVINICH et al., 2014). Dentre os POA, os processos Fenton e foto Fenton têm se destacado em estudos para o tratamento de efluentes de indústrias papeleiras (ARAUJO et al., 2009; COVINICH et al., 2014; NOGUEIRA et al., 2007; XU et al., 2007).

$\mathrm{O}$ processo Fenton caracteriza-se pela reação entre o íon ferroso $\left(\mathrm{Fe}^{2+}\right)$ e o peróxido de hidrogênio $\left(\mathrm{H}_{2} \mathrm{O}_{2}\right)$, conforme ilustrado na Equação 1 (NOGUEIRA et al., 2007). Embora este processo seja uma alternativa eficiente na degradação de vários tipos de poluentes presentes no efluente, seu desempenho pode ser significativamente melhorado quando assistido por fontes de radiação ultravioleta (UV) ou visível (Vis), denominando-se assim sistema foto Fenton (Equação 2).

$$
\begin{gathered}
\mathrm{Fe}^{2+}+\mathrm{H}_{2} \mathrm{O}_{2} \rightarrow \mathrm{Fe}^{3+}+\mathrm{OH}^{-}+\cdot \mathrm{OH}(\text { Equação } 1) \\
\mathrm{Fe}^{3+}+\mathrm{H}_{2} \mathrm{O}+\mathrm{hv} \rightarrow \mathrm{Fe}^{2+}+\cdot \mathrm{OH}+\mathrm{H}^{+}(\text {Equação } 2)
\end{gathered}
$$

A melhora na eficiência do processo quando se adicionam fontes de radiação ocorre, visto que, a fotorredução dos íons férricos ocasiona a regeneração dos íons ferrosos, permitindo assim fechar um ciclo catalítico com formação de dois radicais hidroxila por mol de peróxido de hidrogênio decomposto inicialmente (COVINICH et al., 2014; NOGUEIRA et al., 2007). No entanto, há condições operacionais para a realização destes processos que limitam a sua aplicabilidade. Uma delas é a necessidade de se operar em condições ácidas (pH 2,8 a 3,0), afim de evitar a precipitação de hidróxidos de ferro, os quais interferem na incidência da radiação no sistema, diminuindo a eficiên- 
cia do processo. Além disso, também há a necessidade de um processo adicional após o tratamento para separar precipitados coloidais do efluente final (MUNOZ et al., 2015).

Em decorrência da presença de precipitados de ferro no efluente final, vários trabalhos reportam a utilização de materiais que possuem grupos que permitam formas imobilizadas de íons férrico e/ou ferroso em matrizes orgânicas ou inorgânicas, para o uso em processos fotoquímicos (GONZÁLEZ-BAHAMÓNA et al., 2011; SOUZA et al., 2008). A utilização destas formas imobilizadas permite solucionar problemas relacionados ao cumprimento das legislações vigentes em relação à concentração máxima de ferro no efluente final para poder ser descartado em corpos receptores. Além disso, também permite a ampliação da faixa operacional de $\mathrm{pH}$ no tratamento, a não geração de lodo e a possibilidade de reutilização do sistema imobilizado. Tais fatores representam grande importância no desenvolvimento de um sistema de tratamento em escala industrial.

Dentre os materiais que podem ser utilizados como matriz para imobilização de íons $\mathrm{Fe}^{2+} / \mathrm{Fe}^{3+}$ destaca-se a quitosana, que é o segundo polímero natural mais abundante na natureza, depois apenas da celulose. Está presente como principal constituinte do exoesqueleto de crustáceos aquáticos, além de compor o exoesqueleto de insetos e a parede celular de leveduras e fungos. A estrutura da quitosana está apresentada na Figura 1.

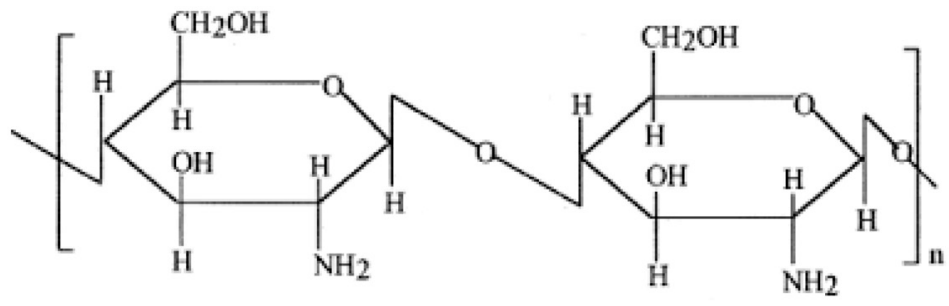

Figura 1. Estrutura química da quitosana.

Figure 1. Chemical structure of chitosan.

A quitosana apresenta importantes propriedades, como baixa toxicidade, é hidrofílica, possui alto potencial para sorção de íons metálicos, é biodegradável, além de apresentar grande importância econômica e ambiental, uma vez que é oriunda de resíduos abundantes e rejeitados pela indústria pesqueira. A quitosana também pode ser facilmente modificada por processos químicos ou físicos para obtê-la em diversas formas, como por exemplo, na forma de esferas (GONSALVES; ARAÚJO, 2011; JANEGITZ et al., 2007).

Diante do exposto, o objetivo do presente trabalho foi avaliar a eficiência do processo foto Fenton utilizando $\mathrm{Fe}^{2+}$ imobilizado em esferas de quitosana como catalisador, bem como a capacidade de reutilização do material, visando dar polimento ao efluente de uma indústria de papel e celulose.

\section{MATERIAL E MÉTODOS}

\section{Efluente}

O efluente utilizado foi cedido por uma indústria de polpa celulósica Kraft e papel embalagem, localizada no Estado do Paraná. A Estação de Tratamento de Efluentes (ETE) da empresa recebe todos os efluentes líquidos oriundos do processo produtivo, totalizando uma vazão média de 450 $\mathrm{m}^{3} /$ hora. As unidades de tratamento compreendem uma lagoa de aeração, seguida por uma lagoa de polimento. O ponto de coleta das amostras para este estudo foi após a lagoa de polimento, caracterizando o efluente final da indústria.

Preparação do catalisador: esferas de quitosana com ferro

O método de preparação da quitosana em forma de esferas foi realizado de acordo com metodologia descrita por Souza et al. (2010). As esferas de quitosana com ferro (EQFe) foram utilizadas como catalisador do processo foto Fenton.

\section{Reator fotoquímico}

Os experimentos foram realizados em um reator de bancada com capacidade de $300 \mathrm{~mL}$, de vidro pirex com parede dupla para permitir a passagem constante de água para a refrigeração do siste- 
Souza et al. - Utilização de biopolímero no tratamento de efluentes

da indústria de papel e celulose por Processo Oxidativo Avançado

ma, conforme ilustrado na Figura 2. O processo foi conduzido com radiação artificial por lâmpada a vapor de mercúrio de $125 \mathrm{~W}$, a qual foi inserida na solução protegida por um bulbo de quartzo e sobre uma placa de agitação magnética.

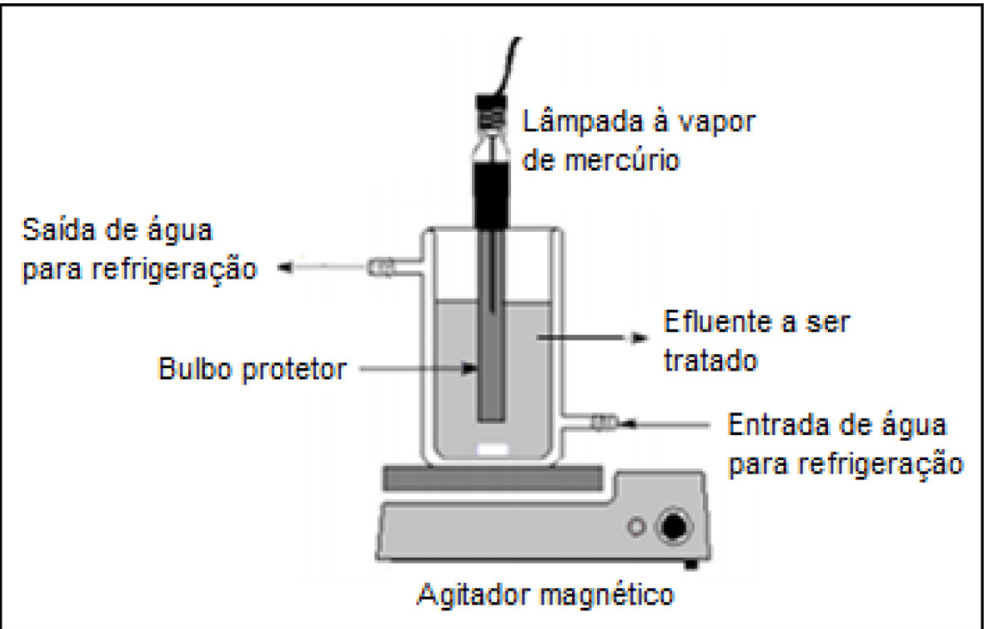

Figura 2. Representação esquemática do reator fotoquímico.

Figure 2. Schematic representation of the photochemical reactor.

\section{Otimização do processo foto Fenton}

$\mathrm{O}$ experimento para o otimização seguiu um delineamento composto central $2^{3} \mathrm{e} e \mathrm{em}$ triplicata. $\mathrm{O}$ efeito dos fatores ( $\mathrm{pH}$, massa de EQFe e concentração de $\mathrm{H}_{2} \mathrm{O}_{2}$ ) na variável resposta, foram avaliados por meio da análise de variância (ANOVA). Foram considerados significativos valores de $\mathrm{p} \leq 0,05$, intervalo de confiança de $95 \%$. Para a otimização, utilizou-se $250 \mathrm{~mL}$ de efluente e as condições testadas foram: $\mathrm{pH}=3,5$ e 7; massa de $\mathrm{EQFe}=2,2,5$ e 3 g e concentração de $\mathrm{H}_{2} \mathrm{O}_{2}=200$, 300 e $400 \mathrm{mg}$. $\mathrm{L}^{-1}$. Foi considerada como variável resposta para a otimização, a porcentagem de descoloração do efluente após 30 minutos.

Foi avaliada também a significância das variáveis utilizando o gráfico de Pareto, o qual é constituído de barras horizontais (correspondentes às variáveis), no qual o comprimento de cada barra é proporcional ao valor absoluto do seu efeito estimado associado ou do efeito padronizado. O gráfico inclui uma linha vertical que indica a significância estatística e que, neste estudo, corresponde ao limite de 95\%. Portanto, os fatores avaliados são significativos se a barra correspondente cruzar esta linha vertical.

\section{Ensaios do processo foto Fenton}

Definidas as melhores condições operacionais das variáveis $\mathrm{pH}$, massa de EQFe e concentração de $\mathrm{H}_{2} \mathrm{O}_{2}$ na etapa anterior, o processo foto Fenton foi aplicado à $250 \mathrm{~mL}$ do efluente com tempo de tratamento igual a 90 minutos. A adição de 400 mg. $\mathrm{L}^{-1} \mathrm{de}_{2} \mathrm{O}_{2}$ foi realizada no início e após 60 minutos de tratamento, totalizando $800 \mathrm{mg} \cdot \mathrm{L}^{-1}$.

Ao final do processo (90 minutos), foram obtidas as amostras para a avaliação da remoção dos parâmetros turbidez, cor aparente, cor verdadeira, demanda química de oxigênio (DQO) e fenóis totais.

\section{Estudo da estabilidade e potencial de reutilização do catalisador}

Também, a partir dos melhores resultados obtidos na otimização do processo foto Fenton relacionados às variáveis $\mathrm{pH}$, massa de EQFe e concentração de $\mathrm{H}_{2} \mathrm{O}_{2}$, foram realizados testes cíclicos para avaliar a estabilidade das EQFe. O experimento de degradação do efluente foi repetido sete vezes (ciclos), sendo que cada ciclo teve duração de 90 minutos. As EQFe foram colocadas no reator fotoquímico para tratar $250 \mathrm{~mL}$ de efluente e, ao final do processo foram recuperadas por filtração simples, lavadas e recolocadas no reator para um novo ciclo de tratamento.

\section{Controle analítico}

A eficiência do processo foi acompanhada pelos seguintes parâmetros, determinados de acordo com metodologia padrão do Standard Methods for the Examination of Water and Wastewater (APHA, 2012): concentrações de $\mathrm{Fe}^{2+}$ e fenóis totais; turbidez; cor aparente e verdadeira e DQO. 
A concentração de $\mathrm{H}_{2} \mathrm{O}_{2}$ foi monitorada de acordo com metodologia descrita por Oliveira et al. (2001) a cada 10 minutos de reação, a fim de verificar a necessidade de reposição do $_{\mathrm{H}_{2}} \mathrm{O}_{2}$, uma vez que o consumo do oxidante depende do tipo de substância presente no efluente.

O acompanhamento do perfil espectrofotométrico foi realizado em espectrofotômetro UV-Vis da HACH modelo 6000, monitorando a região compreendida entre 200 e $700 \mathrm{~nm}$. Todas as medidas foram realizadas em cubetas de quartzo com $1 \mathrm{~cm}$ de caminho ótico.

\section{RESULTADOS E DISCUSSÃO}

\section{Otimização do Processo foto Fenton}

Na Tabela 1 está apresentado o resultado do planejamento fatorial adotado na otimização do processo foto Fenton.

Tabela 1. Planejamento fatorial $2^{3}$ para a otimização das variáveis $\mathrm{pH}$, massa de esferas e concentração de $\mathrm{H}_{2} \mathrm{O}_{2}$. Table 1. Factorial design $2^{3}$ for optimization of $\mathrm{pH}$, mass spheres and $\mathrm{H}_{2} \mathrm{O}_{2}$ concentration.

\begin{tabular}{lcccc}
\hline \multirow{2}{*}{ Experimento } & $\mathbf{p H}$ & Massa EQFe $\mathbf{( g )}$ & {$\left[\mathbf{H}_{\mathbf{2}} \mathbf{O}_{\mathbf{2}}\right] \mathbf{( \mathbf { m g } \cdot \mathbf { L } ^ { - 1 } )}$} & Média Descoloração (\%) \\
\cline { 2 - 4 } 1 & 3 & 2 & 200 & 66,21 \\
2 & 3 & 2 & 400 & 83,80 \\
3 & 3 & 3 & 200 & 66,74 \\
4 & 3 & 3 & 400 & 80,10 \\
5 & 7 & 2 & 200 & 74,74 \\
6 & 7 & 2 & 400 & 89,79 \\
7 & 7 & 3 & 200 & 64,95 \\
8 & 7 & 3 & 400 & 75,68 \\
9 & 5 & 2,5 & 300 & 65,53 \\
\hline
\end{tabular}

Com os resultados do planejamento fatorial, é possível observar que as condições do experimento 6 (2,0 g de EQFe, pH 7 e $400 \mathrm{mg} . \mathrm{L}^{-1}$ de $\left.\mathrm{H}_{2} \mathrm{O}_{2}\right)$, apresentaram maior eficiência na descoloração do efluente, próximo a $90 \%$, em tempo de reação de $30 \mathrm{~min}$, sendo estas as condições selecionadas para as etapas subsequentes. Com relação ao $\mathrm{pH}$, este valor foi próprio ao do efluente, apresentando a vantagem de não serem necessários ajustes no mesmo.

Os resultados da análise dos efeitos principais das variáveis estão representados no gráfico de Pareto $(\mathrm{p}=0,05)$ na Figura 3.

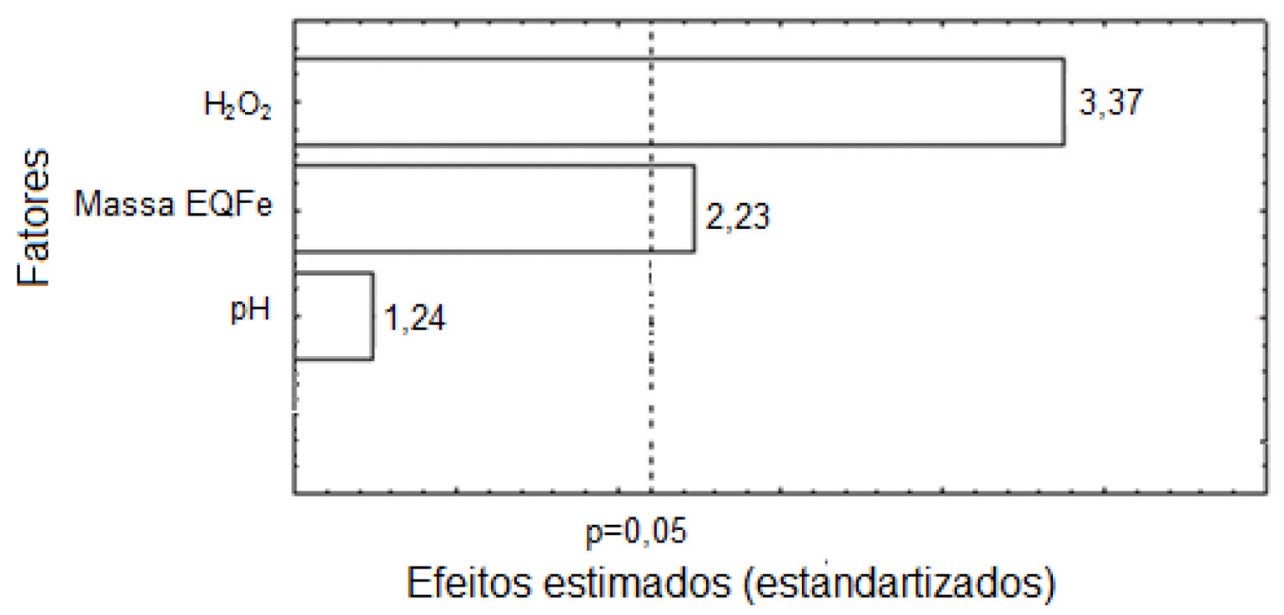

Figura 3. Gráfico de Pareto mostrando a significância das variáveis: concentração de $\mathrm{H} 2 \mathrm{O} 2$, massa de EQFe e pH na descoloração do efluente.

Figure 3. Pareto chart showing the significance of variables: $\mathrm{H} 2 \mathrm{O} 2$ concentration; mass spheres and $\mathrm{pH}$ in the effluent decolorization.

De acordo com os resultados dos efeitos, a massa de EQFe $(\mathrm{p}=0,05)$ e a concentração de $\mathrm{H}_{2} \mathrm{O}_{2}$ $(\mathrm{p}<0,01)$ apresentaram efeitos significativos na eficiência de descoloração do efluente, no entanto, $\mathrm{o}$ que mais influencia na variável resposta é a concentração de $\mathrm{H}_{2} \mathrm{O}_{2}$, uma vez que a barra desta variá- 
Souza et al. - Utilização de biopolímero no tratamento de efluentes

da indústria de papel e celulose por Processo Oxidativo Avançado

vel no gráfico de Pareto foi a que mais ultrapassou a linha vertical. Já o pH $(\mathrm{p}=0,22)$, não apresentou efeito significativo, isto provavelmente, devido a utilização do ferro imobilizado já que, neste caso, não ocorre a formação de precipitado mesmo em valores de $\mathrm{pH}$ superiores a 3.

\section{Aplicação do processo foto Fenton nas condições otimizadas}

Otimizadas as variáveis, o processo foto Fenton foi aplicado ao efluente, com tempo de tratamento de 90 minutos. A Figura 4 apresenta o perfil espectral do efluente na região do UV-Vis.

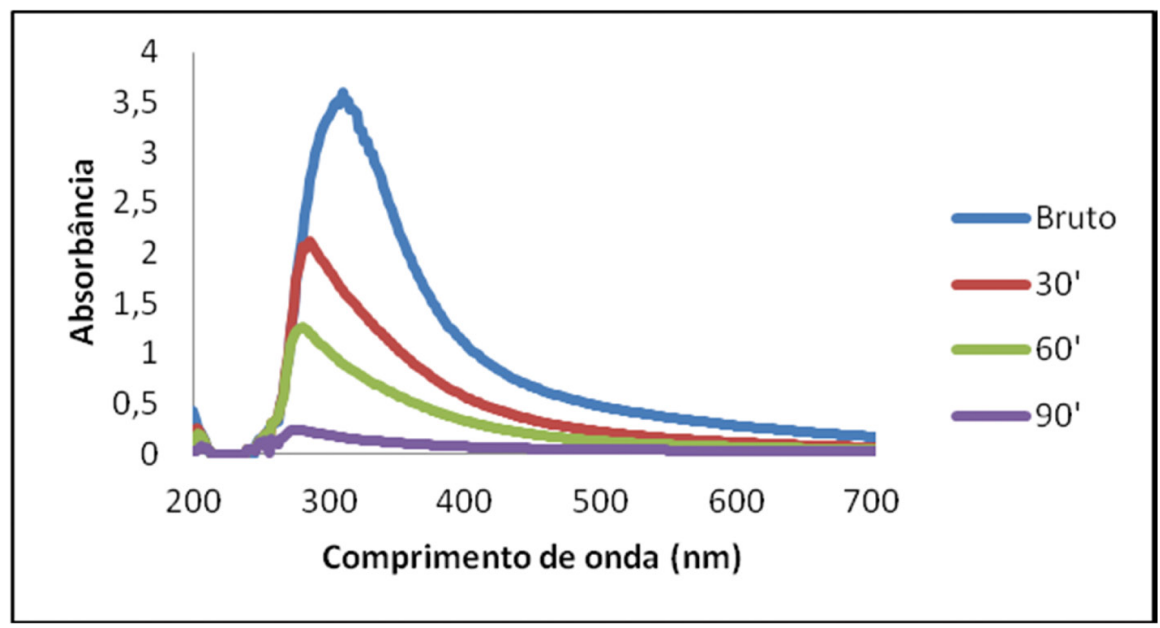

Figura 4. Perfil espectral do efluente pelo processo foto Fenton.

Figure 4. Spectral profile of the effluent by photo Fenton process.

Após 90 minutos de tratamento, tem-se redução de $89 \%$ do sinal na região do visível (compreendida entre 350 e $700 \mathrm{~nm}$ ), a qual representa a redução de cor do efluente. Já a diminuição nas bandas de 200 a $350 \mathrm{~nm}$ corresponde à redução de matéria orgânica, corroborando com as reduções de turbidez (59\%) e de DQO (74,9\%). A concentração de fenóis totais foi determinada e ao final do tratamento houve diminuição de $87,2 \%$ de sua concentração inicial.

Houve um rápido consumo de $\mathrm{H}_{2} \mathrm{O}_{2}$ durante o tratamento, em 60 minutos todo $\mathrm{o}_{2} \mathrm{O}_{2}$ havia sido consumido, sendo necessário neste tempo, adicionar mais oxidante, ou seja, mais $400 \mathrm{mg} . \mathrm{L}^{-1}$ para que a reação de degradação não fosse interrompida, uma vez que o mesmo desempenha grande influência na eficiência do tratamento. Assim, para os 90 minutos de tratamento um total de 800 mg. $\mathrm{L}^{-1}$ de $\mathrm{H}_{2} \mathrm{O}_{2}$ foi necessário.

Ao final do tratamento, a concentração residual de $\mathrm{H}_{2} \mathrm{O}_{2}$ na amostra foi inferior a $10 \mathrm{mg}$. $\mathrm{L}^{-1}$ o que evidencia que o cosumo de oxidante foi maior nos últimos 30 minutos de tratamento. Este comportamento pode ser justificado uma vez que, na degradação de espécies químicas são formados subprodutos durante o processo de oxidação e dependendo da sua estrutura, estes ao serem degradadados consomem mais radicias hidroxila e consequentemente mais $\mathrm{H}_{2} \mathrm{O}_{2}$. Cabe salientar ainda, que a adição de uma dose única de $\mathrm{H}_{2} \mathrm{O}_{2}\left(800 \mathrm{mg} \cdot \mathrm{L}^{-1}\right)$ no início do tratamento não é indicada pois o excesso de $\mathrm{H}_{2} \mathrm{O}_{2}$ pode levar a uma reação competitiva entre o radical hidroxila e o peróxido, produzindo um efeito inibitório na degradação dos compostos (SANTOS et al., 2015)

Na Tabela 2 estão apresentados os valores dos parâmetros avaliados para o efluente bruto e para o efluente após o tratamento proposto.

Tabela 2. Porcentagem de redução dos parâmetros avaliados para o efluente de papel e celulose após 90 minutos de tratamento por processo foto Fenton.

Table 2. Percentage of decrease of evaluated parameters for pulp and paper effluent after 90-minutes treatment by photo-Fenton process.

\begin{tabular}{|c|c|c|c|}
\hline Parâmetro & Efluente Bruto & Efluente Tratado & Porcentagem de Redução \\
\hline $\mathrm{pH}$ & 7 & 7 & - \\
\hline Turbidez (uT) & 32 & 13,1 & 59,0 \\
\hline Cor aparente (mg.L-1 PtCo) & 950 & 108 & 88,6 \\
\hline Cor verdadeira (mg. $\left.\mathrm{L}^{-1} \mathrm{PtCo}\right)$ & 717 & 3 & 99,6 \\
\hline $\mathrm{DQO}\left(\mathrm{mg} \cdot \mathrm{L}^{-1}\right)$ & 275 & 69 & 74,9 \\
\hline Fenóis totais $\left(\mathrm{mg} \cdot \mathrm{L}^{-1}\right)$ & 25 & 3,19 & 87,2 \\
\hline
\end{tabular}


Diante dos resultados apresentados na Tabela 2 é possível observar que o processo foto Fenton promoveu reduções significativas para todos os parâmetros avaliados. No entanto, a concentração de fenóis ainda ficou acima do permitido pela legislação (CONAMA 430/2011), que estabelece no máximo $0,5 \mathrm{mg} . \mathrm{L}^{-1}$ do composto para que o efluente possa ser lançado no corpo receptor. Um dos motivos para a permanência de fenóis mesmo após o tratamento fotoquímico pode ter sido a presença de compostos fenólicos que apresentam estruturas mais complexas e de difícil degradação, como por exemplo, os cresóis, clorofenóis e resorcinol. Estes compostos podem ser encontrados em efluentes de indústria de papel e celulose, mas não foram ainda caracterizados e monitorados de forma sistemática (BRITTO; RANGEL, 2008). Ainda assim, embora a concentração de fenóis tenha ficado acima do estabelecido pela legislação, deve ser observado que o valor encontrado ficou muito mais próximo do estipulado pela Resolução 430/2011, o que pode estimular futuros estudos aplicando outros tipos de processo de oxidação avançada, como por exemplo, ozônio combinado ao $\mathrm{H}_{2} \mathrm{O}_{2^{\prime}}$ de modo a atingir maior eficiência de degradação dos compostos fenólicos, para alcançar os padrões de lançamento exigidos pela legislação.

Padrões de lançamento para alguns parâmetros (como turbidez e cor verdadeira) não são expressos na Resolução CONAMA 430/2011. No entanto, deve-se observar a Resolução CONAMA 357/2005, que trás os requisitos mínimos de qualidade da água a serem atendidos no corpo d'água que recebe o efluente, após a mistura do mesmo e em condições de vazão de referência do corpo receptor, ou seja, vazões críticas. Os valores dos parâmetros turbidez e cor verdadeira obtidos nesta pesquisa tem potencial para atender a Resolução CONAMA 357/2005, mesmo caso o lançamento do efluente seja feito em corpos hídricos de classes mais restritivas.

Não há relatos na literatura sobre a aplicação de processo foto Fenton utilizando ferro imobilizado para tratamento de efluentes de papel e celulose, por isso a comparação dos resultados obtidos no presente trabalho foi realizada com trabalhos que utilizaram o processo foto Fenton com ferro em solução.

No trabalho desenvolvido por Rabelo (2005) foi avaliada a aplicação combinada de dois processos de tratamento de efluentes de indústria de celulose kraft branqueada, o processo foto Fenton e lodos ativados, sendo que estudou-se a aplicação do processo oxidativo antes e depois do tratamento biológico. Para fins de comparação, tomaram-se como base apenas os resultados obtidos com o processo oxidativo com irradiação artificial aplicado após o processo biológico. O melhor resultado obtido por Rabelo (2005) foi uma redução de 73,5\% da DQO e ocorreu para as seguintes condições: pH do efluente igual a 3, tempo de tratamento de 120 minutos, concentração de $\mathrm{H}_{2} \mathrm{O}_{2}$ e $\mathrm{Fe}^{2+}$ aplicadas de 2000 e $200 \mathrm{mg} . \mathrm{L}^{-1}$, respectivamente. Este resultado foi muito similar ao obtido no presente estudo, no entanto, o resultado da literatura foi com tempo de reação e concentração dos reagentes bem superiores. Ressalta-se então, que foi possível manter o pH 7 originário do efluente, usar cinco vezes menos peróxido de hidrogênio, com 30 minutos a menos de tratamento, condição que ainda resultou em uma redução de DQO superior; o que comprova a possibilidade da utilização de formas imobilizadas de ferro, as quais permitem uma importante ampliação da faixa operacional de $\mathrm{pH}$, além da possibilidade de reutilização do material.

De acordo com os resultados satisfatórios de degradação do efluente obtidos utilizando as EQFe, associado ao fato de que estas não sofreram alterações estruturais durante o processo, tornou-se relevante a realização do estudo preliminar quanto à estabilidade do catalisador e possibilidade de reutilização das esferas.

\section{Estabilidade do catalisador e reutilização}

As EQFe foram utilizadas em sete ciclos. Os valores remanescentes de cada parâmetro avaliado (em todos os ciclos) estão apresentadas na Tabela 3.

Os resultados expostos na Tabela 3 indicam a possibilidade de reutilização do catalisador por 6 ciclos, apresentando estabilidade em sua atividade e manutenção de sua estrutura. Até o sexto ciclo o processo permaneceu com elevada eficiência na remoção dos parâmetros cor, turbidez, DQO e fenóis, com valores muito próximos ao primeiro ciclo. Já no sétimo ciclo, as esferas começaram a perder estrutura, o que acarretou em um aumento da turbidez, da cor, e principalmente da DQO, em decorrência da decomposição do polímero. 
Souza et al. - Utilização de biopolímero no tratamento de efluentes

da indústria de papel e celulose por Processo Oxidativo Avançado

Tabela 3. Resultados dos parâmetros avaliados após o primeiro e o sétimo ciclos das esferas no tratamento do efluente.

Table 3. Results of evaluated parameters after the first and the seventh cycles of spheres in the treatment effluent.

\begin{tabular}{|c|c|c|c|c|c|c|c|c|}
\hline \multirow{2}{*}{ Parâmetros avaliados } & \multirow{2}{*}{ Efluente bruto } & \multicolumn{7}{|c|}{ Ciclos } \\
\hline & & $1^{\circ}$ & $2^{\circ}$ & $3^{\circ}$ & $4^{\circ}$ & $5^{\circ}$ & $6^{\circ}$ & $7^{\circ}$ \\
\hline Turbidez (uT) & 32,0 & 13,1 & 13,5 & 14,3 & 13,9 & 15,4 & 17,2 & 25,3 \\
\hline Cor aparente (mg. $\left.\mathrm{L}^{-1} \mathrm{PtCo}\right)$ & 950,1 & 108,3 & 108,0 & 109,3 & 109,4 & 110,1 & 110,0 & 124,1 \\
\hline Cor verdadeira (mg. $\left.\mathrm{L}^{-1} \mathrm{PtCo}\right)$ & 717,0 & 3,0 & 3,5 & 3,2 & 4,8 & 6,0 & 6,2 & 7,5 \\
\hline $\mathrm{DQO}\left(\mathrm{mg} \cdot \mathrm{L}^{-1}\right)$ & 275,0 & 69,1 & 68,8 & 70,1 & 71,5 & 71,0 & 71,4 & 180,2 \\
\hline Fenóis totais $\left(\mathrm{mg} \cdot \mathrm{L}^{-1}\right)$ & 25,0 & 3,2 & 3,5 & 3,3 & 3,7 & 3,8 & 3,7 & 3,9 \\
\hline
\end{tabular}

Durante as reutilizações foi monitorada a concentração de ferro dissolvido no efluente a fim de avaliar a possível liberação do mesmo para o meio. Resultados demonstraram que a concentração de ferro em solução foi inferior ao limite de detecção da curva analítica $\left(0,25 \mathrm{mg}\right.$. $\left.\mathrm{L}^{-1}\right)$, até o sexto ciclo, o que indica que o mesmo permaneceu sorvido na matriz. Já no sétimo ciclo, a concentração de ferro em solução foi de 20 mg. $\mathrm{L}^{-1}$, uma vez que as esferas se desmancharam. Com esses resultados, fica evidente que o limite de utilização das EQFe é de seis ciclos, sem perda de eficiência dos parâmetros avaliados.

Yang et al. (2014) estudaram a degradação de corante azo utilizando como catalisador $\mathrm{Fe}^{2+} \mathrm{em}$ carvão ativado, o qual permaneceu estável em cinco ciclos testados, com eficiência de degradação de aproximadamente $98 \%$ em todos os ciclos, mantendo o teor de ferro no material.

\section{CONCLUSÕES}

De acordo com os resultados, pode-se verificar que o processo foto Fenton, utilizando quitosana como matriz para imobilização de íons $\mathrm{Fe}^{2+}$, mostra-se como uma alternativa eficiente de pós-tratamento de efluente de indústria de papel e celulose, principalmente para o parâmetro cor, turbidez e DQO. Já para a redução de compostos fenólicos, o processo promove reduções significativas, porém sugere-se a combinação a outros processos de tratamento para que atenda aos limites preconizados na Resolução CONAMA 430/2011.

Foi possível ainda, atestar a capacidade de reutilização das EQFe por seis ciclos, com a manutenção da eficiência de remoção dos parâmetros avaliados similares entre o primeiro e o sexto ciclo.

\section{AGRADECIMENTOS}

Fundação Araucária.

\section{REFERÊNCIAS BIBLIOGRÁFICAS}

APHA-AWWA-WEF. Standart Methods for Examination of Water and Wastewater. 19ed. Washington: American Public Health Association, 2012.

ARAUJO, A. L. P.; COSSICH, E. S.; TAVARES, C. R. G. Remoção de DQO de Efluente de Indústria de Celulose e Papel empregando Reagente Fenton. Scientia Plena, Aracajú, v. 5, n. 7, 2009.

BONFIM, L. T.; SILVA, D. F.; SOUZA, J. B.; CAVALLINI, G. S.; LESS, F. R. Análise da eficiência do conjunto coagulação/precipitação no pós-tratamento de efluente de uma indústria de papel e celulose. Revista de Engenharia e Tecnologia, Ponta Grossa, v. 5, n. 3, p. 15-24, 2013.

BRASIL. Ministério do Meio Ambiente, Conselho Nacional do Meio Ambiente, CONAMA. Resolução CONAMA n n $^{\text {430/11, de }} 13$ de maio de 2011 - In: Resoluções, 2005. Disponível em: < http://www.mma.gov. br > Acesso em: 23. fev.2016. 
BRASIL. Ministério do Meio Ambiente, Conselho Nacional do Meio Ambiente, CONAMA. Resolução CONAMA n ${ }^{0}$ 357/05, de 17 de março de 2005 - In: Resoluções, 2005. Disponível em: < http://www.mma. gov.br> Acesso em: 23. fev. 2016.

BRITTO, J. M.; RANGEL, M. C. Processos avançados de oxidação de compostos fenólicos em efluentes industriais. Química Nova, São Paulo, v.31, n. 1, p.114-122, 2008.

COVINICH, L. G.; BENGOECHEA, D. I.; FENOGLIO, R. J.; AREA, M. C. Advanced oxidation processes for wastewater treatment in the pulp and paper industry: A review. American Journal of Environmental Engineering, Rosemead, v. 4, n. 3, p. 56-70, 2014.

GONSALVES, A. A.; ARAÚJO, C. R. M. Diferentes estratégias para a reticulação de quitosana. Química Nova, São Paulo, v. 34, n. 7, p. 1215-1223, 2011.

GONZÁLEZ-BAHAMÓNA, L. F.; MAZILLEB, F.; BENÍTEZA, L. N.; PULGARÍNB, C. photo Fenton degradation of resorcinol mediated by catalysts based on iron species supported on polymers. Journal of Photochemistry and Photobiology A: Chemistry, v. 217, n. 1, p. 201-206, 2011.

IBÁ - INDÚSTRIA BRASILEIRA DE ÁRVORES. Dados do Setor. 2015. Disponível em: < http://iba.org/images/ shared/iba 2015.pdf >. Acesso em: 18. fev. 2016.

JANEGITZ, B. C.; LOURENÇÃO, B. C.; LUPETTI ,K. O.; FATIBELLO-FILHO, O. Desenvolvimento de um método empregando quitosana para remoção de íons metálicos de águas residuárias. Química Nova, São Paulo, v. 30, n. 4, p. 879-884, 2007.

KAMALI, M.; KHODAPARAS, Z. Review on recent developments on pulp and paper mill wastewater treatment. Ecotoxicology and Environmental Safety, v.114, p.326-342, 2015.

MUNOZ, M.; DE PEDRO, Z. M.; CASAS, J. A.; RODRIGUEZ, J. J. Preparation of magnetite-based catalysts and their application in heterogeneous Fenton oxidation - A review. Applied Catalysis B: Environmental, v.176177, p.249-265, 2015.

NOGUEIRA, R. F. P.; TROVÓ, A. G.; SILVA, M. R.A.; VILLA, R.D. Fundamentos e Aplicações ambientais dos processos fenton e foto Fenton. Química Nova, São Paulo, v. 30, n. 2, p. 400-408, 2007.

OLIVEIRA, M. C.; NOGUEIRA, R. F. P.; NETO, J. A. G. Sistema de injeção em fluxo espectrofotométrico para monitorar peroxido de hidrogênio em processo de fotodegradação por reação foto Fenton. Química Nova, São Paulo, v. 24, n. 2, p. 188-190, 2001.

PEREIRA, W. S.; FREIRE, R. S. Ferro zero: uma nova abordagem para o tratamento de águas contaminadas com compostos orgânicos poluentes. Química Nova, São Paulo, v. 28, n. 1, p. 130-136, 2005.

RABELO, M. D. Avaliação da aplicação combinados dos processos foto-Fenton e biológico no tratamento de efluentes de indústria de celulose kraft branqueada. 2005. 102 p. Tese (Doutorado em Agroquímica) Universidade Federal de Viçosa, Viçosa, 2005.

SANTOS, L. V.; MEIRELES, A. M.; LANGE, L. C. Degradation of antibiotics norfloxacin by Fenton, UV and UV/ $\mathrm{H}_{2} \mathrm{O}_{2}$. Journal of Environmental Management, New York, v. 154, p. 8-12, 2015.

SOUZA, K.V.; ZAMORA, P.G.P.; ZAWADZKI, S.F. Imobilização de ferro (II) em matriz de alginato e sua utilização na degradação de corantes têxteis por processos Fenton. Química Nova, São Paulo, v. 31, n. 5, p. 1145-1149, 2008. 
Souza et al. - Utilização de biopolímero no tratamento de efluentes

da indústria de papel e celulose por Processo Oxidativo Avançado

SOUZA, K. V.; ZAMORA, P. G. P.; ZAWADZKI, S. F. Esferas de Quitosana/Fe na Degradação do Corante Azul QR-19 por Processos Foto-Fenton Utilizando Luz Artificial ou Solar. Polímeros: Ciência e Tecnologia,v. 20, n. 3, p. $210-214,2010$.

XU, M.; WANG, Q.; HAO,Y. Removal of organic carbon from wastepaper pulp effluent by lab-scale solar photo-Fenton process. Journal of Hazardous Materials, v.148, p.103-109, 2007.

YANG, C.; WANG, D.; TANG, Q. The synthesis of NdFeB magnetic activated carbon and its application in degradation of azo dye methyl orange by Fenton like process. Journal of the Taiwan Institute of Chemical Engineers, Taipe, v. 45, n. 5, p.2584-2589, 2014.

Recebido em 12/07/2016

Aceito para publicação em 06/03/2017 